\title{
Crack Initiation and Endurance Limit of Hard Steels under Multiaxial Cyclic Loads
}

\author{
H. Bomas, ${ }^{\text {1,a }}$ R. Kienzler, ${ }^{2}$ S. Kunow, ${ }^{3}$ G. Loewisch, ${ }^{4}$ and R. Schroeder ${ }^{2}$ \\ ${ }^{1}$ Stiftung Institut für Werkstofftechnik, Bremen, Germany \\ ${ }^{2}$ University of Bremen, Bremen, Germany \\ ${ }^{3}$ Edelstahlwerke Südwestfalen, Siegen, Germany \\ ${ }^{4}$ Universität der Bundeswehr, Neubiberg, Germany \\ ${ }^{a}$ bomas $(a)$ iwt-bremen.de
}

The endurance limit and the mechanisms of fatigue crack initiation in the high cycle regime were investigated using round specimens of the bearing steel 52100 under longitudinal forces and torsional moments and combinations of these loads. Three specimen types were examined: smooth specimens and specimens with circumferential notches with radii of 1.0 and $0.2 \mathrm{~mm}$. The influence of mean and multiaxial stresses on the endurance limit can be understood by consideration of crack initiation mechanisms and micro-mechanics. Crack initiation took place at oxides, carbonitrides and at the surface. The mechanisms of crack initiation could be related to the load type: Loads with rotating principal stresses are more damaging for nitrides than for oxides. Increasing maximum stresses are more dangerous for nitrides than for oxides, and introduce more damage to the surface than to the nitrides. Normal stresses are more damaging for oxides than shear stresses. The endurance limits were calculated by means of an extended weakest-link model which combines volume and surface crack initiation with related fatigue criteria. For volume crack initiation the criterion of Dang Van was used. For the correct description of the competing surface crack initiation, a new criterion was applied. With this concept, a prediction of the endurance limit is possible for loads which produce critical planes and range within a limited regime of stress ratios.

Keywords: endurance limit, bearing steel, crack initiation, multiaxial load, weakest-link model, fatigue criterion.

Introduction. This paper describes a calculation method for hard steels which allows the prediction of the endurance limit of parts of arbitrary geometry based on data that have been gained from tests on a set of reference specimens under certain load conditions. For the development of this calculation method, the endurance limits of smooth and notched specimens under tension-compression, repeated tension, alternating torsion and different superpositions of cyclic tensile and torsional loads have been determined experimentally. Hereby, the influence of mean stresses, multiaxial stress conditions and stress gradients on the fatigue behavior could be evaluated. Based on the collected data, a calculation method was applied which is based on the weakest-link model [1] and on suitable high-cycle fatigue criteria for surface and volume crack initiation $[2,3]$.

Material and Specimens. The experiments were carried out on the bearing steel SAE 52100 remelted under vacuum. From this material, smooth and notched specimens were turned with a net diameter of $d=6 \mathrm{~mm}$ (Fig. 1). After turning, the specimens were heat treated as follows: $855^{\circ} \mathrm{C}, 25 \mathrm{~min} / \mathrm{salt}$ melt $220^{\circ} \mathrm{C}, 6 \mathrm{~h} /$ washing $65^{\circ} \mathrm{C}$. In this bainitic condition the material had a hardness of $715 \mathrm{HV} 10$ and the following tensile properties: $R_{m}=2467 \mathrm{MPa}, R_{p 02}=2115 \mathrm{MPa}$, and $E=202 \mathrm{GPa}$. Finally, the specimens were ground in the gauge region, which resulted in the following residual stresses at the surface of the smooth specimens: $-479 \mathrm{MPa}$ in the longitudinal direction and $-384 \mathrm{MPa}$ in the tangential direction.

(C) H. BOMAS, R. KIENZLER, S. KUNOW, G. LOEWISCH, R. SCHROEDER, 2008 

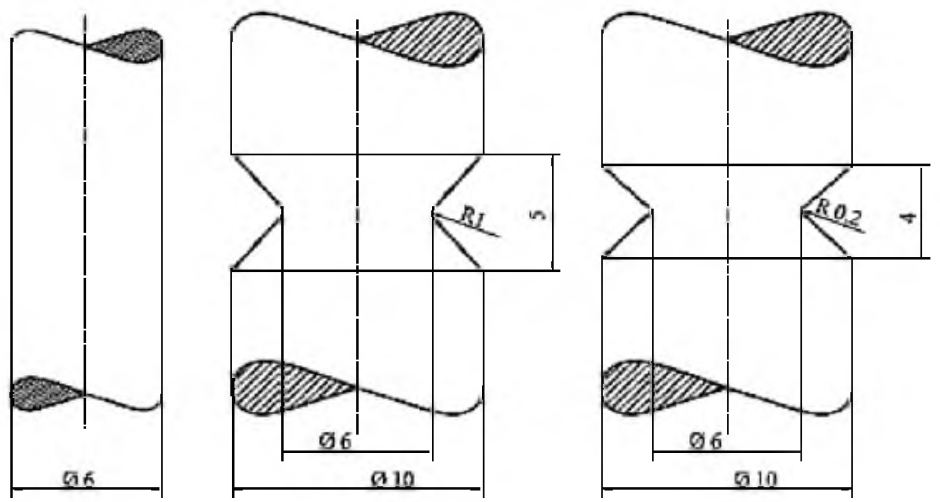

Fig. 1. Geometry of the fatigue specimens in the gauge region.

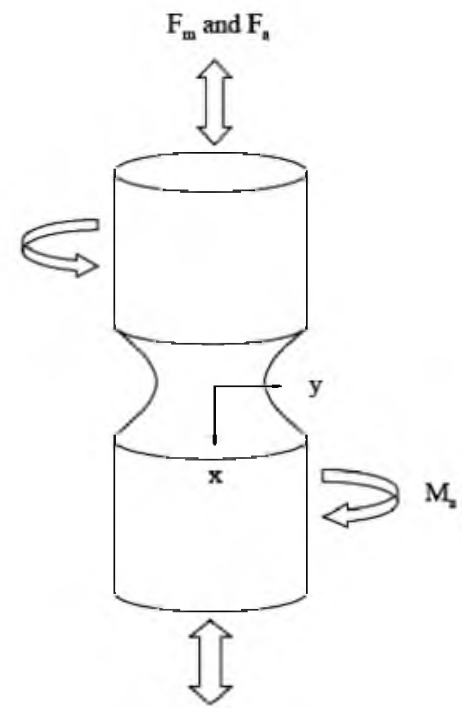

Fig. 2. Loading of a notched specimen and relevant coordinates at the notch root surface, $x=$ coordinate parallel to the rotation axis, $y=$ tangential coordinate.

Endurance Limits. The specimens were cycled in a testing system that allows the superposition of longitudinal and torsional loads (Fig. 2). The applied loads can be described with a mean longitudinal load $F_{m}$, a corresponding amplitude $F_{a}$, and an amplitude $M_{a}$ of the torsional moment. Longitudinal load and torsional moment were cycled with the same frequency $f$ and combined in phase or with a phase shift $\delta=\pi / 2$. The resulting surface load stress tensor at the notch root has the following form:

$$
\left(\begin{array}{ccc}
\sigma_{x}=\sigma_{m}+\sigma_{a} \sin (2 \pi f t) & \tau_{x y}=\tau_{a} \sin (2 \pi f t+\delta) & 0 \\
\tau_{y x}=\tau_{a} \sin (2 \pi f t+\delta) & 0 & 0 \\
0 & 0 & 0
\end{array}\right) .
$$

The endurance limits under different load types were determined by constant amplitude tests at different amplitudes. Endurance of a specimen was defined as reaching $10^{7}$ cycles without failure. The endurance limits were assumed to obey a two-parametric Weibull distribution: 


$$
F\left(S_{a}\right)=1-2^{-\left(S_{a} / S_{D}\right)^{m}}, \quad F\left(T_{a}\right)=1-2^{-\left(T_{a} / T_{D}\right)^{m}} .
$$

Table 1 gives a survey over the tested variants and the measured endurance limits.

$\mathrm{T}$ a b 1 e 1

Experimental Variants and Corresponding Endurance Limits

\begin{tabular}{|c|c|c|c|c|c|c|c|c|}
\hline Variant & $S_{a}$ & $R_{S}$ & $T_{a}$ & $\delta$ & $\begin{array}{c}\text { Notch radius } \\
{[\mathrm{mm}]}\end{array}$ & $\begin{array}{c}\text { Endurance limit } \\
{[\mathrm{MPa}]}\end{array}$ & $m$ & $\begin{array}{l}\text { Symbol } \\
\text { in Fig. } 4\end{array}$ \\
\hline 1 & $S_{a}$ & -1 & 0 & & $\infty$ & 866 & 20 & + \\
\hline 2 & $S_{a}$ & -1 & 0 & & 1.0 & 631 & 23 & + \\
\hline 3 & $S_{a}$ & -1 & 0 & & 0.2 & 373 & 9 & + \\
\hline 4 & $S_{a}$ & 0.1 & 0 & & $\infty$ & 502 & 21 & + \\
\hline 5 & $S_{a}$ & 0.4 & 0 & & $\infty$ & 437 & 48 & + \\
\hline 6 & $S_{a}$ & 0.5 & 0 & & $\infty$ & 419 & 51 & + \\
\hline 7 & $S_{a}$ & 0.6 & 0 & & $\infty$ & 371 & 33 & + \\
\hline 8 & 0 & & $T_{a}$ & & $\infty$ & 540 & 55 & $x$ \\
\hline 9 & 0 & & $T_{a}$ & & 1.0 & 539 & 16 & $\times$ \\
\hline 10 & 0 & & $T_{a}$ & & 0.2 & 334 & 20 & $\times$ \\
\hline 11 & $S_{a}$ & -1 & $0.5 S_{a}$ & 0 & $x$ & 734 & 19 & * \\
\hline 12 & $S_{a}$ & -1 & $0.5 S_{a}$ & 0 & 1.0 & 520 & 14 & * \\
\hline 13 & $S_{a}$ & -1 & $0.5 S_{a}$ & 0 & 0.2 & 345 & 13 & * \\
\hline 14 & $S_{a}$ & -1 & $0.5 S_{a}$ & $\pi / 2$ & $\infty$ & 607 & 45 & 0 \\
\hline 15 & $S_{a}$ & -1 & $0.5 S_{a}$ & $\pi / 2$ & 1.0 & 406 & 25 & 0 \\
\hline 16 & $S_{a}$ & -1 & $0.5 S_{a}$ & $\pi / 2$ & 0.2 & 283 & 6 & 0 \\
\hline 17 & $S_{a}$ & -1 & $S_{a}$ & $\pi / 2$ & $\infty$ & 431 & 11 & 0 \\
\hline 18 & $S_{a}$ & 0.1 & $0.5 S_{a}$ & $\pi / 2$ & $\infty$ & 417 & 31 & 0 \\
\hline 19 & $S_{a}$ & -1 & $S_{a}$ & 0 & $\infty$ & 477 & 7 & * \\
\hline
\end{tabular}

Fatigue Crack Initiation. Three types of crack initiation were observed: crack initiation at the surface, at aluminum oxides and in titanium carbonitrides. The latter two types are shown in Fig. 3. Crack initiation at aluminum oxides is due to matrix failure, since the inclusion is not bonded to the matrix und thus concentrates the stress in the surrounding matrix. Crack initiation in titanium carbonitrides is due to failure of the inclusion itself, since the inclusion is well bonded to the matrix and concentrates the stress in itself. The cracks exhibit cleavage of the inclusion in well defined crystal planes. All notched specimens exhibited crack initiation at the surface which is due to the stress gradient.

Table 2 shows the crack initiation sites in smooth specimens. Several tendencies can be observed: Under tensile loads starting from a stress ratio $R=-1$, the titanium carbonitrides get more involved in crack initiation as the stress ratio increases to $R=0.1$. Further increase of the stress ratio leads to more frequent crack initiation at the surface. Torsional loads are obviously most dangerous for the surface. A comparison of proportional loading and non-proportional loading shows that the titanium carbonitrides are mostly damaged by non-proportional loading. 
Crack Initiation and Endurance Limit of Hard Steels...

$\mathrm{T}$ a b l e 2

Observed Crack Initiation Sites in Smooth Specimens

\begin{tabular}{|c|c|c|c|c|c|}
\hline Variant & $S_{a}$ & $R_{S}$ & $T_{a}$ & $\delta$ & Crack initiation at $S_{a}<S_{90}$ \\
\hline 1 & $S_{a}$ & -1 & 0 & & $\begin{array}{l}33 \% \text { aluminum oxide } \\
45 \% \text { titanium carbonitride } \\
22 \% \text { unknown }\end{array}$ \\
\hline 4 & $S_{a}$ & 0.1 & 0 & & $100 \%$ titanium carbonitride \\
\hline 5 & $S_{a}$ & 0.4 & 0 & & $\begin{array}{c}77 \% \text { titanium carbonitride } \\
23 \% \text { surface }\end{array}$ \\
\hline 6 & $S_{a}$ & 0.5 & 0 & & $\begin{array}{c}11 \% \text { aluminum oxide } \\
33 \% \text { titanium carbonitride } \\
56 \% \text { surface }\end{array}$ \\
\hline 7 & $S_{a}$ & 0.6 & 0 & & $\begin{array}{c}29 \% \text { titanium carbonitride } \\
71 \% \text { surface }\end{array}$ \\
\hline 8 & 0 & & $T_{a}$ & & $100 \%$ surface \\
\hline 11 & $S_{a}$ & -1 & $0.5 S_{a}$ & $0^{c}$ & $\begin{array}{c}63 \% \text { aluminum oxide } \\
32 \% \text { titanium carbonitride } \\
5 \% \text { surface }\end{array}$ \\
\hline 14 & $S_{a}$ & -1 & $0.5 S_{a}$ & $90^{\circ}$ & $\begin{array}{c}67 \% \text { titanium carbonitride } \\
8 \% \text { surface } \\
25 \% \text { unknown }\end{array}$ \\
\hline
\end{tabular}

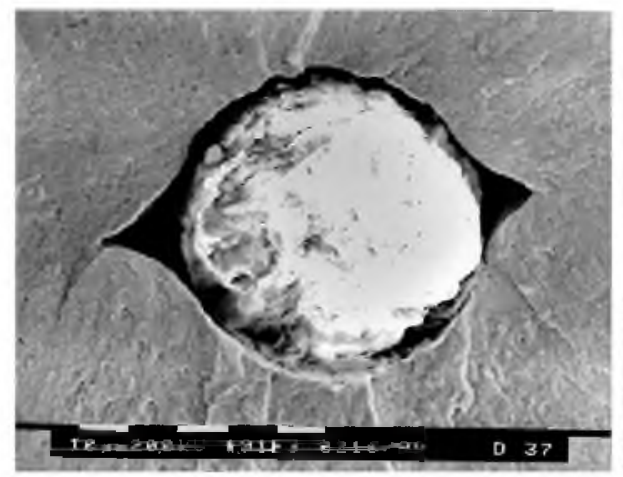

a

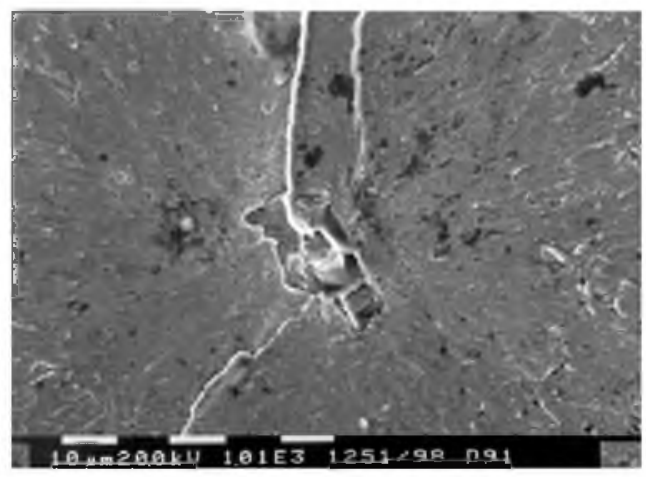

b

Fig. 3. Crack initiation at an aluminum oxide (a) and at a titanium carbonitride (b).

Calculation of Endurance Limits. The endurance limits were calculated on the basis of the weakest-link concept, as described before [2]. For crack initiation in the volume Dang Van's criterion [3] was applied, which uses the equivalent value $\tau_{a \text {, max }}+$ $\alpha_{V} p_{\max }$. For crack initiation at the surface a criterion of Bomas, Linkewitz, and Mayr [2] was applied, which uses the equivalent value $\tau_{a \text { max }}+\alpha_{A} p_{m}$. The model parameters shown in Table 3 were determined by taking the variants $1,2,4,8$, and 9 as references. Figure 4 shows the calculated and the measured endurance limits as nominal stress amplitudes $S_{a}$ or $T_{a}$. Most endurance limits are well calculated. Large differences between experiment and calculation are exhibited by the variants $5,6,7,14$, and 15 .

The variants 5, 6, and 7 exhibit high stress ratios of $R=0.4,0.5$, and 0.6 , respectively. If the endurance limits of these variants are drawn in the Haigh diagram with 
H. Bomas, R. Kienzler, S. Kunow, et al.

the values of the variants 1 and 4 , it can be seen that there is a non-linear relation between endurance limit and mean stress. This is typical for hard steels, e.g., [4], but is not described by the applied fatigue criteria.

$\mathrm{T}$ a b 1 e 3

Model Parameters for Calculation of the Endurance Limits

\begin{tabular}{|c|c|c|c|c|}
\hline & Reference area or volume & $\tau_{W 0}, \mathrm{MPa}$ & $\alpha$ & $m$ \\
\hline Surface $A$ & $A_{0}=213 \mathrm{~mm}^{2}$ & 551 & 1.32 & 10 \\
\hline Volume $V$ & $V_{0}=192 \mathrm{~mm}^{3}$ & 629 & 0.59 & 14 \\
\hline
\end{tabular}

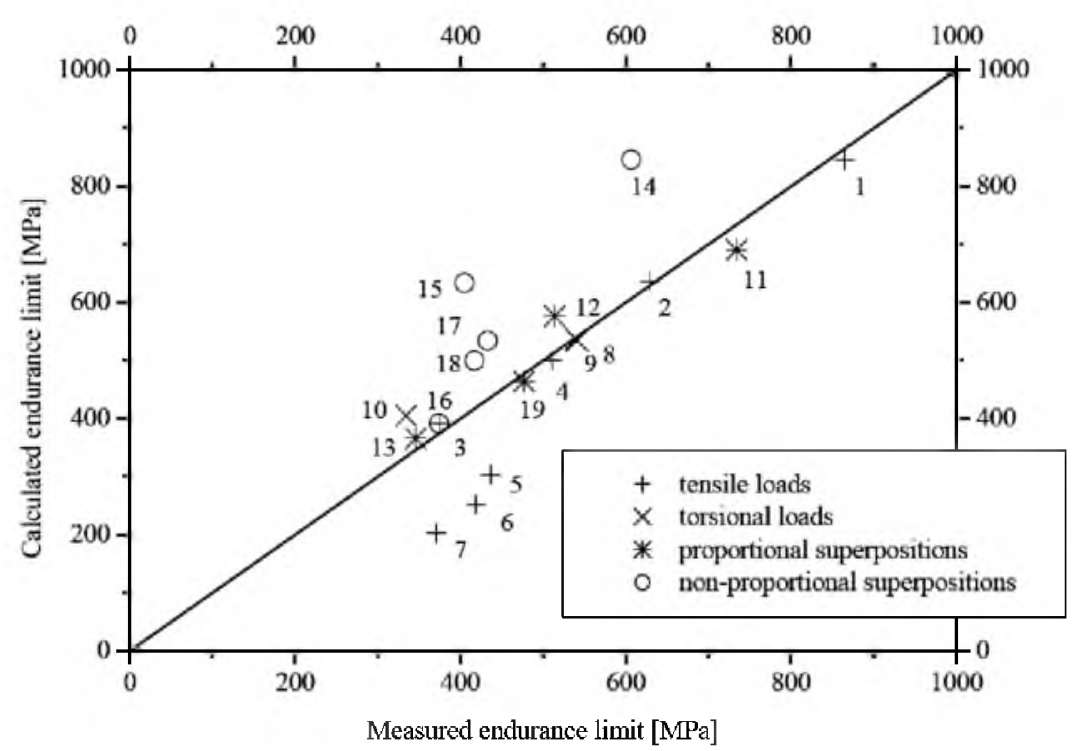

Fig. 4. Predicted and measured nominal endurance limits, expressed as nominal longitudinal stress $S_{n}$ or nominal torsional stress $T_{n}$.

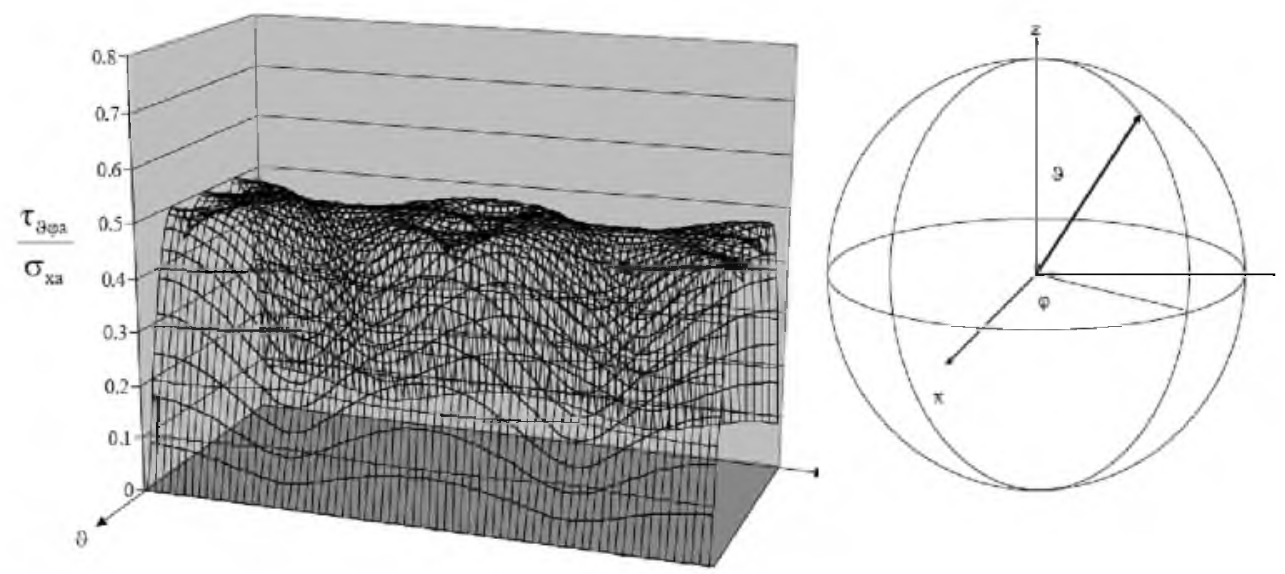

Fig. 5. Surface shear stress amplitudes in a specimen of variant 14 normalised with the normal stress amplitude in $x$-direction $\left(0 \leq \vartheta \leq 180^{\circ}, 0 \leq \varphi \leq 360^{\circ}\right)$. An explanation of the cartesian coordinates is given in Fig. 2. 
The variants 14 and 15 are phase-shifted superpositions of tension and torsion. Variant 14 is very special, because it has no critical plane. Figure 5 shows the shear stress amplitudes in the cutting surface planes normalised with the normal stress amplitude in $x$-direction. $\vartheta$ and $\varphi$ indicate the direction of vector normal to the plane. Since many planes see the maximum shear stress amplitude, the damage of the load is underestimated by the applied fatigue criteria. Especially the titanium carbonitrides seem to be victims of the multi-plane damage, since they fail by cleavage fracture in crystal planes. The specimens of variant 15 have a mild notch, and the stress situation is similar to that of variant 14 . The specimens of variant 16 have a sharp notch, and due to the dominance of the stress concentration factor for tension, the stress situation in the notch root is more similar to that of variant 3 . It can be seen in Fig. 4 that the endurance limits of these variants are very similar, which applies for the experimental values as well as for the calculated ones.

Conclusions. In this work, the influence of notches, stress gradients, mean stresses and multiaxial loads on the endurance limit of ground specimens made of the bearing steel SAE 52100 in a bainitic condition was investigated. The influence of notches and of stress gradients can be described by application of a weakest-link concept. A prediction of the endurance limit is possible for loads with $-1 \leq R \leq 0.1$ which produce critical planes. The crack initiation in smooth specimens is very much influenced by the load type. Three crack initiation sites were observed: oxides, carbonitrides and surface. Loads that produce more than one critical plane lead to further damage of the titanium carbonitrides. Under push-pull or repeated-pull condition the maximum stress is relevant for crack initiation: With increasing maximum stress, at first titanium carbonitrides and after that the surface get more and more involved in crack initiation.

1. W. Weibull, "A statistical theory for the strength of materials," Royal Swed. Inst. Eng. Res., 151 (1939).

2. H. Bomas, T. Linkewitz, and P. Mayr, Fatigue Fract. Eng. Mater. Struct, 22, 733 (1999).

3. K. Dang Van, B. Griveau, and O. Message, in: M. W. Brown and K. J. Miller (Eds.), Biaxial and Multiaxial Fatigue (EGF 3), Mechanical Engineering Publications (1989), p. 479.

4. E. Haibach, Betriebsfestigkeit, Springer (2002). 